\section{ECCOMAS}

\section{Proceedia}

COMPDYN 2021

$8^{\text {th }}$ ECCOMAS Thematic Conference on Computational Methods in Structural Dynamics and Earthquake Engineering

M. Papadrakakis, M. Fragiadakis (eds.)

\title{
CONTINUOUS AND DISCONTINUOUS DESCRIPTIONS OF BLOCKED STRUCTURES: THE CASE STUDY OF SANTISSIMO CROCIFISSO CHURCH IN PRETARE (ITALY)
}

\author{
F. Clementi ${ }^{1}$, A. Ferrante ${ }^{2}$, E. Giordano ${ }^{2}$ and S. Lenci ${ }^{1}$ \\ ${ }^{1}$ Department of Civil and Building Engineering, and Architecture, Polytechnic University of Marche, \\ via Brecce Bianche, 60131, Ancona, Italy \\ e-mail: \{francesco.clementi, s.lenci\}@univpm.it \\ ${ }^{2}$ Department of Civil and Building Engineering, and Architecture, Polytechnic University of Marche, \\ via Brecce Bianche, 60131, Ancona, Italy \\ e-mail: \{a.ferrante, e.giordano\}@pm.univpm.it
}

\begin{abstract}
Advanced numerical modelling of the masonry "Apennine Church" of Santissimo Crocifisso in Pretare, Arquata del Tronto (AP), was here utilized to have an insight into the dynamic properties and behavior of the structure under strong nonlinear dynamic excitations. The objectives were achieved by comparing nonlinear dynamic analyses through discontinuous and continuous approaches. In the discrete element approach, the Non-Smooth Contact Dynamics method, implemented in LMGC90 C, was applied, adopting a full 3D detailed discretization. The Church was schematized as an arrangement of discrete rigid blocks, subjected to sliding by friction and perfect plastic collisions, governed by Signorini's impenetrability condition and dry-friction Coulomb's law, with a null restitution coefficient. In the finite element approach, the Concrete Damaged Plasticity model available in Midas FEA NX® was involved. This model allows reproducing the tensile cracking, the compressive crushing, and the degradation of the material under cyclic loads. At the end, the structure exhibited a complex dynamic behavior, because of the geometrical nonlinearity and the non-smooth nature of the contact laws. Finally, the numerical analyses provided a valuable picture of the actual behavior of the church, which is mandatory for future strengthening interventions.
\end{abstract}

Keywords: Masonry, Dynamics, Nonlinear Dynamic Analysis, Non-Smooth Contact Dynamics Method, Concrete Damaged Plasticity. 


\section{INTRODUCTION}

Over the years Italy has seen a succession of strong and frequent seismic events. This predisposition is because the peninsula is located on two tectonic plates, the Eurasian and the African, which by pushing themselves accumulate energy that causes earthquakes when released. The boundary line of these tectonic plates covers all the Apennines and the Alps, which are precisely the places where strong seismic events have developed most frequently. The most recent sequence took place between 2016 and 2017 and hit the mountain area of four regions of Central Italy: Abruzzo, Lazio, Marche, and Umbria. As visible in Figure 1, the first strong shock of magnitude 6.0 was recorded on $24^{\text {th }}$ August 2016 with epicenter between the municipalities of Accumoli, Amatrice and Arquata del Tronto. This was the shock that caused most of the damage to the town of Arquata del Tronto, in fact there was a level of damage of the X degree of the European Macroseismic Scale (EMC). In the following days and months, nine thousand tremors were recorded, of which nine with a magnitude equal to or greater than 5 [1]. Relevant were those of $26^{\text {th }}$ October 2016 with magnitude 5.4 and epicenter between Castelsantangelo sul Nera, Visso, Ussita and Preci and that of October $30^{\text {th }} 2016$ of magnitude 6.5 with epicenter between Norcia, Castelsantangelo sul Nera and Preci.

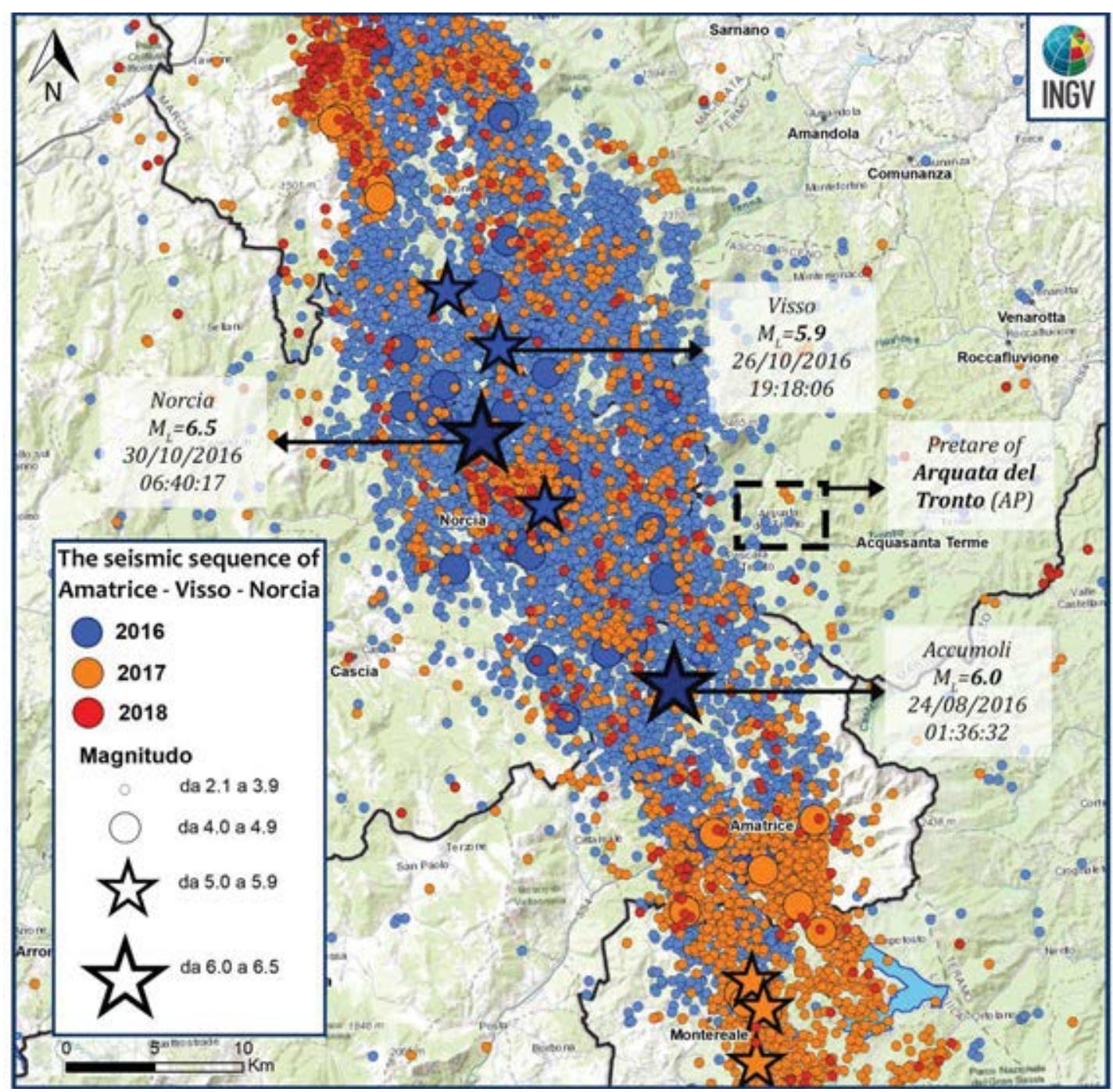

Figure 1: The Central Italy seismic sequence of 2016 (source: http://itaca.mi.ingv.it) and the geographic location of Pretare in the municipality of Arquata del Tronto (AP). 
The case study analyzed in this research work is the Santissimo Crocifisso Church located in Pretare, municipality of Arquata del Tronto in the province of Ascoli Piceno (AP) (Marche region, Central Italy). For its position near the epicenters of the main strong motions, the structure suffered severe damages during the 2016 seismic sequence. To investigate in depth the nonlinear behavior of the structure, comparative work was carried out on continuous and discontinuous approaches applying the Concrete Damaged Plasticity (CDP) model and the Non-Smooth Contact Dynamics (NSCD) method, respectively. Other applications on towers [2-5] and churches [6-8] are introduced in the literature, but a comparison of these methods has not yet been developed.

\section{HISTORICAL AND GEOMETRIC DESCRIPTION OF THE CHURCH}

The origins of the Santissimo Crocifisso Church are not known and the first information showing its existence dates to the $15^{\text {th }}$ century, when it was dedicated to Santa Maria della Cecca. During these years, the church was used sporadically and left in a state of neglect. The first restoration interventions were executed between 1910 and 1911. In these years, the church was almost completely rebuilt, the interior paintings were realized and the two niches on the lateral walls were created. After this restoration, the church was dedicated to the Santissimo Crocifisso in honor of an ancient wooden crucifix recovered from the old parish. In 1950 the church was deconsecrated and used as a parish theater. After the works of 1970 (reconstruction of the roof, reconstruction of the floor, and construction of the steeple in reinforced concrete (RC)) the church was reopened for worship. After the 1997 Umbria-Marche earthquake, the church presented extended damages. In the years 2014-2015 a new restoration was carried out, including interventions to improve the structural response. The masonry was reinforced with interventions of "scuci e cuci" and injection of mortar. A steel curb was inserted at the top main façade and the wooden roof was completely rebuilt. Finally, the church suffered severe damages following the 2016 Central Italy earthquakes, until its closure for safeguard reasons. Indeed, after these events, the church exhibited deep cracks and masonry disaggregation damages on the upper part of the main façade and extended cracks at the connections of the nave walls (see Figure 2). All of the masonry walls introduce the activation of overturning mechanisms.
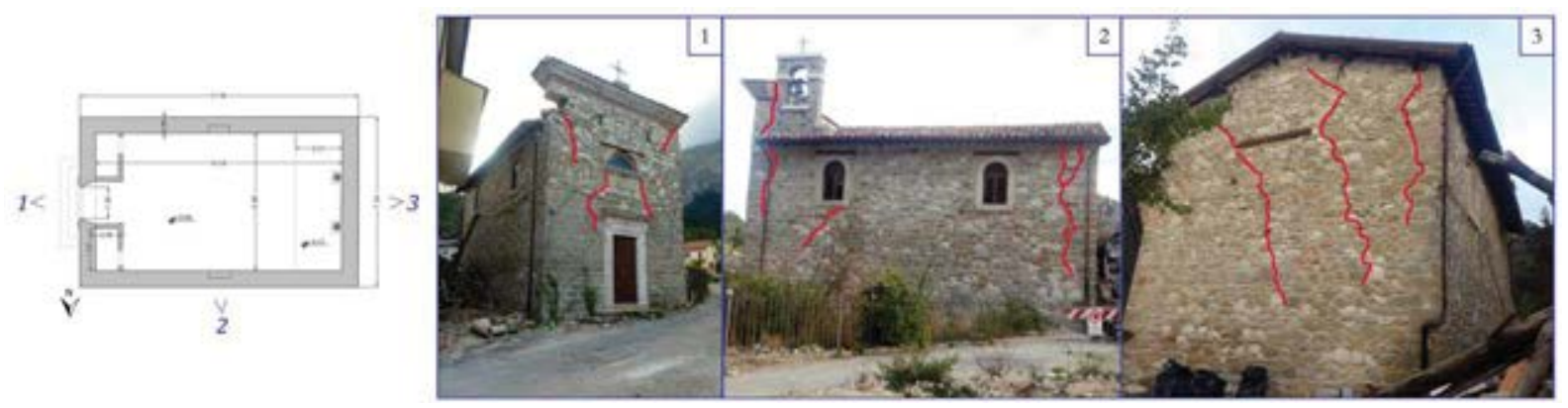

Figure 2: Crack pattern of the Santissimo Crocifisso Church in Pretare (Arquata del Tronto, AP) after the earthquakes of 2016 on 1) the main façade and the 2) North and 3) West facades.

From a geometric point of view, the structure introduces a rectangular plan measuring $11.94 \mathrm{~m} \times 7.24 \mathrm{~m}$ and it is covered by light vaults in camorcanna, as visible in Errore. L'origine riferimento non è stata trovata. The structure reaches a maximum height of $10.59 \mathrm{~m}$ in correspondence with the steeple. Two single arched openings are on the lateral sides of the nave and a semicircular opening is located above the portal of the main facade. The bearing masonry structure is characterized by local stone and travertine. The steeple and the curb at 
the top of the main facade are built with reinforced concrete. Finally, the roof is made of chestnut wood.

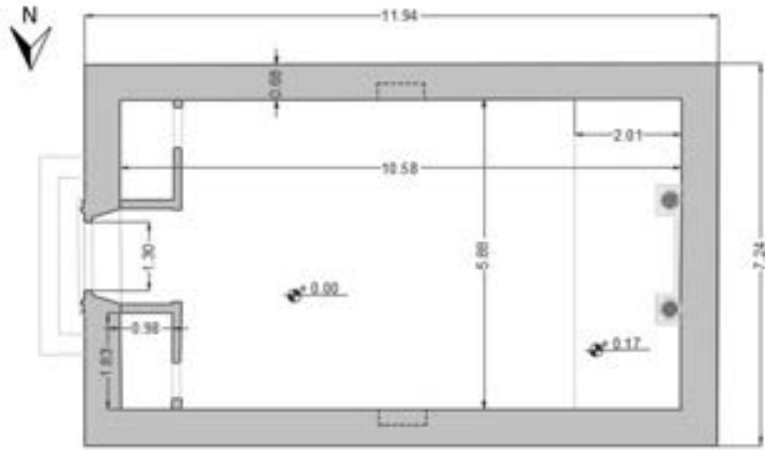

(a)

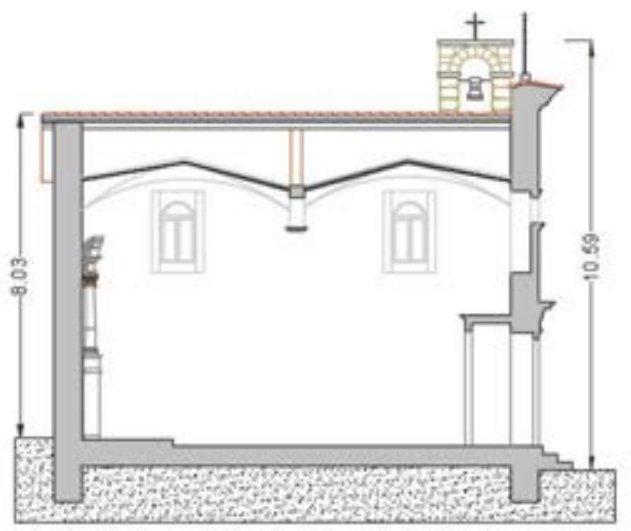

(c)

Figure 3: Geometric configuration of the Santissimo Crocifisso Church in Pretare (Arquata del Tronto, AP).

\section{COMPARISON OF THE FINITE AND DISCRETE ELEMENT}

In this comparative work, the FEM and DEM modeling are used to analyze the case study. Both models were subjected to nonlinear dynamic analyses considering the three main shocks of the 2016 Central Italy sequence: $24^{\text {th }}$ August $2016,26^{\text {th }}$ October 2016 , and $30^{\text {th }}$ October 2016. The events recorded in the surrounding area of the church and in the epicenters were applied at the base of the FE and DE models in Figure 4. Strong motions of 10 seconds were considered in sequence, with 5 seconds of rest among them.
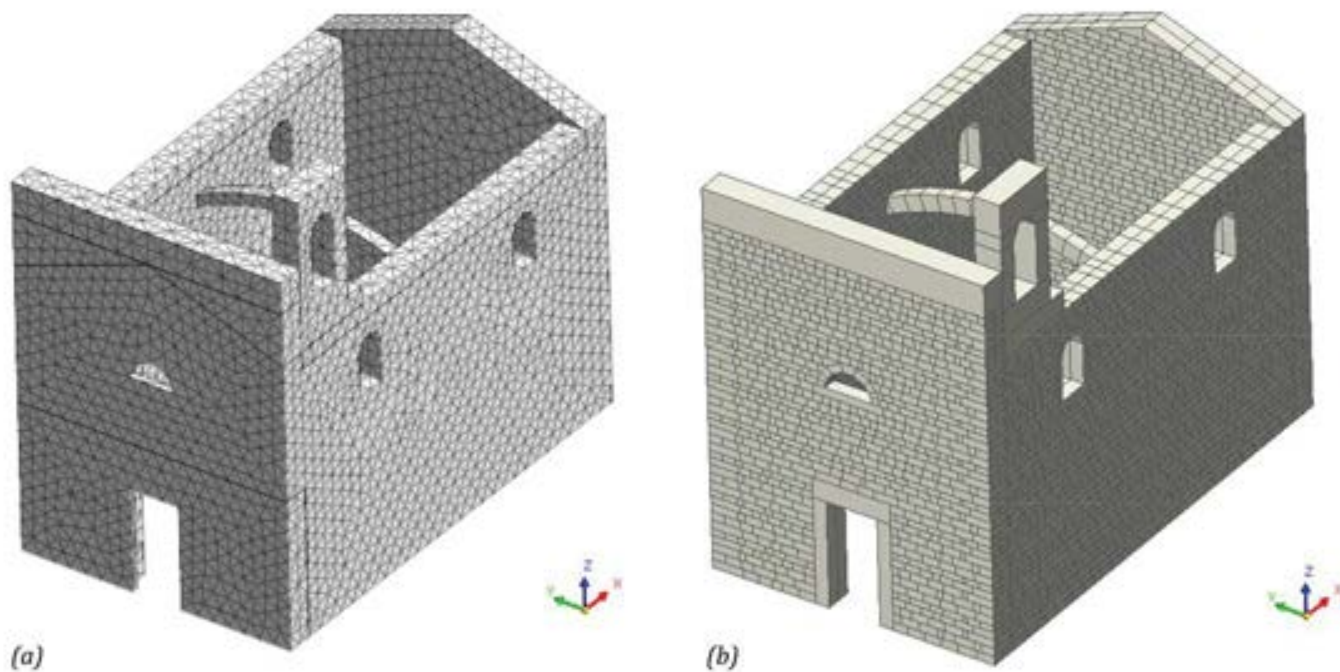
Figure 4: a) FE and b) DE models of the Santissimo Crocifisso Church in Pretare (Arquata del Tronto, AP).

\subsection{Finite Element model}

The continuous model was accurately reproduced using tetrahedral 3D elements of average size $0.4 \mathrm{~m}$. In total the model is composed of 23020 elements, 6283 nodes and 19782 degrees of freedom (see Figure 4a). The foundations were simulated by preventing both the displacements and the translations of the base nodes, while the presence of the camorcanna vaults was taken into consideration as an additional mass on the lateral walls of the nave.

To simulate the nonlinear behavior of the masonry, the Concrete Damage Plasticity Method (CDP) implemented in the Midas FEA NX(C) software was used. This type of modeling developed by Lubliner [9] and implemented by Lee \& Fenves [10] was initially used for the study of reinforced concrete but subsequently proved to be optimal also for simulating fragile materials such as masonry $[11,12]$.

Starting from the indications in the literature [13], it has been assumed that the masonry obeys a Drucker-Prager resistance criterion with an unassociated flow rule. The surface of this criterion was deformed through a coefficient $\mathrm{K}_{\mathrm{c}}$, to resemble that of Mohr-Coulomb, while the tip of the cone was beveled to avoid numerical convergence problems through an eccentricity parameter. To consider, the ratio between biaxial and mono axial ultimate compressive strength, it was considered with an appropriate ratio between $\mathrm{f}_{\mathrm{bo}}$ and $\mathrm{f}_{\mathrm{co}}$. In addition, the dilatancy angle and the viscosity parameter were defined. The mechanical parameters applied in the CDP model are reported in Table 1. The nonlinear behavior of the masonry was defined assigning suitable inelastic mono-axial stress-strain curves in traction and compression.

\begin{tabular}{ll}
\hline Parameter & Value \\
\hline Dilatancy angle $\left(^{\circ}\right)$ & 10 \\
Eccentricity & 0.1 \\
fbo $_{\text {f }}$ co & 1.16 \\
$\mathrm{~K}_{\mathrm{c}}$ & 0.667 \\
Viscosity Parameter & 0 \\
\hline
\end{tabular}

Table 1: Mechanical parameters of CDP model

\subsection{Discrete Element model}

The discontinuous model reproduces the masonry structure through an assembly of 3D blocks modeled similarly to the existing masonry texture. The complex model is composed by a total of 7636 blocks (see Figure 4b).

The NSCD method belongs to the family of DE models, distinguishing from the classical Distinct Element Method (DEM) for three differences: (i) it integrates the non-smooth contact laws directly, (ii) it uses an implicit integration scheme, and (iii) it does not account for any structural damping. It is important to stress the fact that the NSCD method is based on some modelling simplifications. The main assumption is that bodies are rigid. Since the contact between blocks is governed by the Signorini's impenetrability condition and the dry-friction Coulomb's law, the churches exhibit discontinuous dynamics. Regarding the contacts between bodies, the above-mentioned relations imply perfectly plastic impact, i.e., the Newton law with restitution coefficient equal to zero, which does not account for bounces after impact. This presents two main advantages: (i) the contribution of impacts to the computational complexity is modest since they are modelled in a very basic and simple way; (ii) since the impact is perfectly plastic, it dissipates energy, and, from a mechanical viewpoint, this is a way to account for material damages and micro-cracks, which form in the stones at impact, and, from 
a computational point of view, dissipation contributes to the stability of the numerical integration. In addition, the friction contributes to dissipation, but damping, a fundamental ingredient of continuum models, is not considered here.

\subsection{Critical discussion}

For brevity of the paper, the main results of the nonlinear dynamic analyses under the seismic actions recorded near the church location and performed with the CDP model and NSCD method are plotted Figure 5a and Figure 5b, respectively. A good match between the numerical damages and the existing crack pattern (see Figure 2) is reached. The resultant behaviors explain the relevant applicability of these methods in order to obtain similar failures despite the different laws that govern the two approaches.

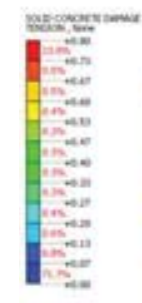

(a)
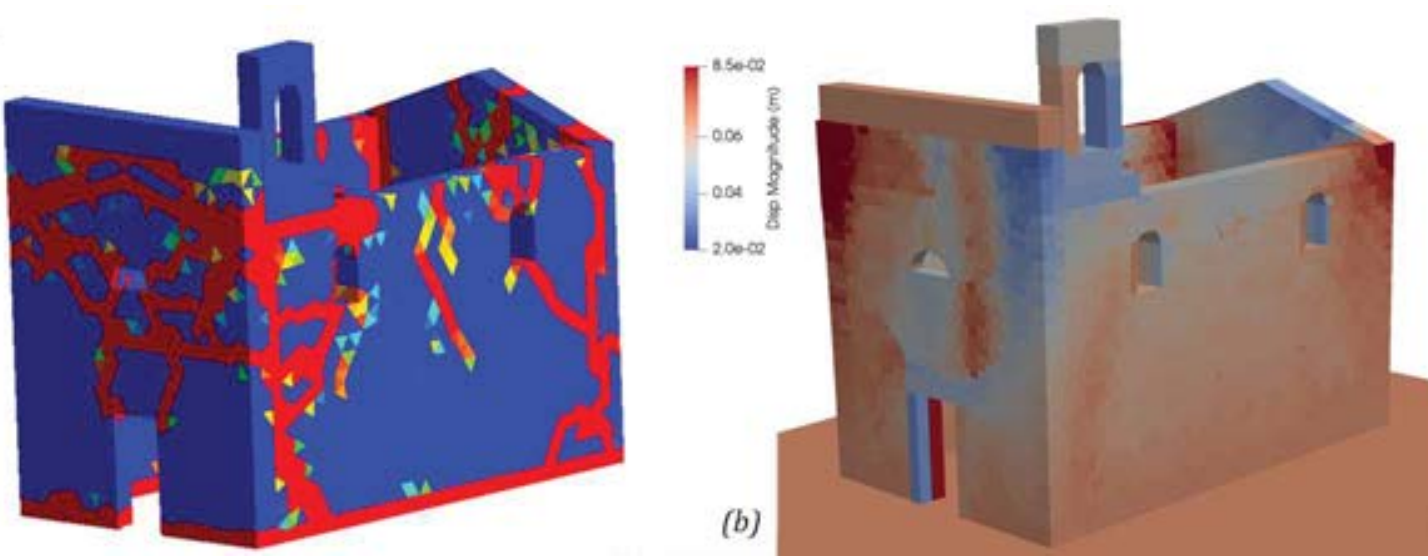

Figure 5: Comparison of the numerical damages of the Santissimo Crocifisso Church in Pretare (Arquata del Tronto, AP) resulting from the nonlinear dynamic analyses with 1) the CDP model and 2) the NSCD method.

\section{CONCLUSIONS}

The numerical modeling of the Santissimo Crocifisso Church in Pretare, Arquata del Tronto (AP), was carried out by means of advanced FE and DE models. The relevance of the findings is related to the deep investigation of the masonry nonlinear response. The seismic actions registered near the church leads to the validation of both continuous and discontinuous methods through a good match with real cracks of the structure. The application of the epicentral seismic actions allows to obtain a development of the failure mechanisms with the amplification of the damages. All these numerical results appear to be interesting in light of design the retrofitting works. Indeed, the complex nonlinear behavior of the church is clearly pointed out with CDP model. Moreover, the NSCD method allows to investigate the local failure mechanisms, as the masonry disaggregation which is neglected in FEM.

\section{REFERENCES}

[1] Dipartimento di Protezione Civile, I numeri del sisma del Centro Italia, 2018.

[2] A. Ferrante, F. Clementi, G. Milani, Advanced numerical analyses by the Non-Smooth Contact Dynamics method of an ancient masonry bell tower, Math. Methods Appl. Sci. (2020). https://doi.org/10.1002/mma.6113.

[3] A. Ferrante, D. Loverdos, F. Clementi, G. Milani, A. Formisano, S. Lenci, V. Sarhosis, 
Discontinuous approaches for nonlinear dynamic analyses of an ancient masonry tower, Eng. Struct. 230 (2021) 111626. https://doi.org/10.1016/j.engstruct.2020.111626.

[4] A. Ferrante, F. Clementi, G. Milani, Dynamic Behavior of an Inclined Existing Masonry Tower in Italy, Front. Built Environ. 5 (2019). https://doi.org/10.3389/fbuil.2019.00033.

[5] G. Standoli, E. Giordano, G. Milani, F. Clementi, Model Updating of Historical Belfries Based on Oma Identification Techniques, Int. J. Archit. Herit. (2020) 1-25. https://doi.org/10.1080/15583058.2020.1723735.

[6] F. Clementi, A. Ferrante, E. Giordano, F. Dubois, S. Lenci, Damage assessment of ancient masonry churches stroked by the Central Italy earthquakes of 2016 by the nonsmooth contact dynamics method, Bull. Earthq. Eng. (2019). https://doi.org/10.1007/s10518-019-00613-4.

[7] E. Giordano, F. Clementi, A. Nespeca, S. Lenci, Damage Assessment by Numerical Modeling of Sant'Agostino's Sanctuary in Offida During the Central Italy 2016-2017 Seismic Sequence, Front. Built Environ. 4 (2019). https://doi.org/10.3389/fbuil.2018.00087.

[8] G. Milani, M. Valente, Failure analysis of seven masonry churches severely damaged during the 2012 Emilia-Romagna (Italy) earthquake: Non-linear dynamic analyses vs conventional static approaches, Eng. Fail. Anal. 54 (2015) 13-56. https://doi.org/10.1016/j.engfailanal.2015.03.016.

[9] J. Lubliner, J. Oliver, S. Oller, E. Oñate, A plastic-damage model for concrete, Int. J. Solids Struct. 25 (1989) 299-326. https://doi.org/10.1016/0020-7683(89)90050-4.

[10] J. Lee, G.L. Fenves, Plastic-Damage Model for Cyclic Loading of Concrete Structures, J. Eng. Mech. 124 (1998) 892-900. https://doi.org/10.1061/(ASCE)07339399(1998)124:8(892).

[11] G. Milani, M. Valente, Comparative pushover and limit analyses on seven masonry churches damaged by the 2012 Emilia-Romagna (Italy) seismic events: Possibilities of non-linear finite elements compared with pre-assigned failure mechanisms, Eng. Fail. Anal. 47 (2015) 129-161. https://doi.org/10.1016/j.engfailanal.2014.09.016.

[12] R. Illampas, I. Ioannou, P.B. Lourenço, Seismic appraisal of heritage ruins: The case study of the St. Mary of Carmel church in Cyprus, Eng. Struct. 224 (2020) 111209. https://doi.org/10.1016/j.engstruct.2020.111209.

[13] G. Milani, M. Valente, C. Alessandri, The narthex of the Church of the Nativity in Bethlehem: A non-linear finite element approach to predict the structural damage, Comput. Struct. 207 (2018) 3-18. https://doi.org/10.1016/j.compstruc.2017.03.010. 